\title{
Joint Capsule
}

National Cancer Institute

\section{Source}

National Cancer Institute. Joint Capsule. NCI Thesaurus. Code C84388.

Dense fibrous connective tissue sealing the joint. It is attached to the bones and provides stability. 